\title{
STOCHASTICS AND STATISTICS IN STUDY OF EDUCATION FOR ELEMENTARY SCHOOL TEACHERS
}

\section{[STOCHASTIKA A STATISTIKA VE STUDIU UCITELSTVI PRO 1. STUPEN ZAKLADNI SKOLY]}

\author{
Jan Melichar
}

\section{doi: 10.18355/PG.2016.5.1.14-20}

\begin{abstract}
Author presents way of education of stochastics and statistics during study of elementary school teaching. Students come out from real impulses, they proceed from informal processes to formal processes that are connected with reality up to formal mathematics. Students are solving problem situations starting from games focused on statistics and probability up to use of statistics and probability in connection with the theory of heredity. Students are led to inquiry-based learning.
\end{abstract}

\section{Key words}

stochastics, statistics, games focused on statistics and probability, heredity, genotype, phenotype, inquiry-based learning

\begin{abstract}
Abstrakt
Autor ukazuje způsob výuky stochastiky a statistiky ve studiu učitelství pro 1. stupeň základní školy. Studenti vycházejí z reálných podnětů, postupují od neformálních postupů spjatých s realitou až $\mathrm{k}$ tomu, co je přijatelné jako formální matematika. Studentům jsou předkládány problémové situace, které řeší. Od her, kde je využita pravděpodobnost a statistika přecházejí studenti nenásilně k využití pravděpodobnosti a statistiky v teorii dědičnosti. Studenti jsou vedeni k badatelsky orientované výuce.
\end{abstract}

\section{Klíčová slova}

stochastika, statistika, hry s využitím pravděpodobnosti, dědičnost, genotyp, fenotyp, badatelsky orientovaná výuka

\section{Úvod}

Na Pedagogické fakultě Univerzity Jana Evangelity Purkyně v Ústí nad Labem ve studiu učitelství pro 1. stupeň základní školy věnuji pozornost v předmětu Didaktika matematiky stochastice a statistice na základě podnětů, které jsem získal při spolupráci s Pedagogickou univerzitou v polském Krakově jmenovitě s Prof. Dr.hab Adamem Plockým. Při výuce vycházíme $\mathrm{z}$ realistického př́stupu k vyučování matematice, kdy studenti vycházejí z reálných podnětů, postupují od neformálních postupů spjatých $\mathrm{s}$ realitou až k tomu, co je přijatelné jako formální matematika. Studentům jsou předkládány problémové situace, které řeší. 
Výuka statistiky je v úzké souvislosti se stochastikou, t. j. naukou o počtu pravděpodobnosti (probabilitou). Souvislost mezi stochastikou a matematickou statistikou spočívá $v$ tom, že stochastika usuzuje z vytvořeného pravděpodobnostního modelu zkoumaného děje na jeho průběh a aby u matematické statistiky byl průběh opačný, aby vlastnosti tohoto modelu byly odhadovány na základě zjištěných dat $\mathrm{z}$ jeho realizace.

Ukažme si na př́iklady z výuky:

Úloha 1: Hrají dva hráči. Házíte dvěma stejnými mincemi. Váš úkol je zvolit si předem na stálo jednu z možností, které padnou a za tuto př́znivou možnost dostanete bod. Obdobně učiní protihráč. Kdo získá více bodů vyhraje. Kterou z možností je výhodné typovat?

Jsou možné tři výsledky hodu dvěma stejnými mincemi:

$\mathrm{h}_{1}$ : padnou dva ruby,

$\mathrm{h}_{2}$ : padnou dva líce,

$\mathrm{h}_{3}$ : padne rub a líc.

Prostorem výsledků této hry je množina $\mathbf{M}=\left\{\mathrm{h}_{1}, \mathrm{~h}_{2}, \mathrm{~h}_{3}\right\}$, každá úsečka reprezentuje jeden z výsledků (Obrázok 1).

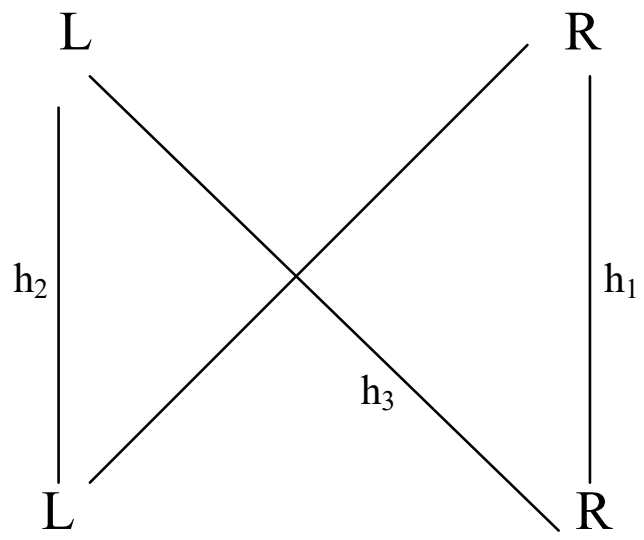

Obrázok 1 Pravděpodobnost jevu $h_{1}$ je tedy $1 / 4$, jevu $h_{2}$ je také $1 / 4$ a jevu $h_{3} 1 / 2$.

Úloha 2: Hrají dva hráči. V neprůhledném losovacím zařízení mají dvě koule modré a dvě koule červené. Hráči si zvolí předem, na stálo, možnost bud' vytáhnout koule stejné barvy anebo dvě koule různé barvy. Koule se do osudí vracejí. Hráči za svojí volbu dostanou bod. Je tato hra spravedlivá? Prostor výsledků této hry lze znázornit (Obrázok 2). Koule stejné barvy znázorňuje zelená úsečka, koule různé barvy černá úsečka. 


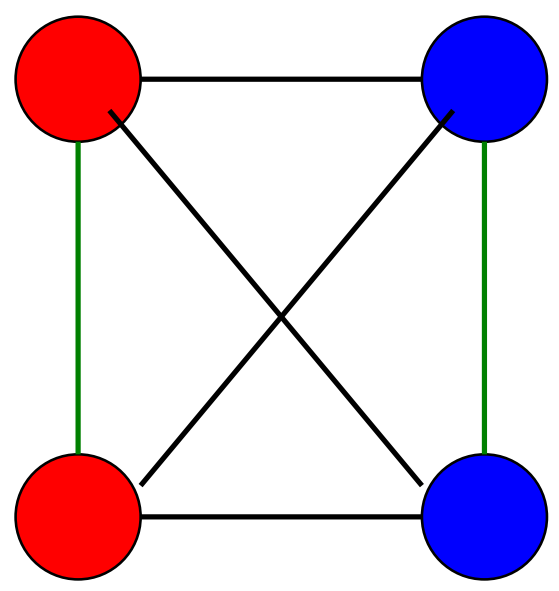

Obrázok 2

Pravděpodobnost jevu $\boldsymbol{s}$ koule stejné barvy jsou $2 / 6$, což je $1 / 3$ a pravděpodobnost jevu $\boldsymbol{r}$ koule různé barvy 4/6, což jsou 2/3. Hra je nespravedlivá a ten kdo si zvolí koule různé barvy vždy vítězí.

Studentům jsem zadal problémovou úlohu: Kolik musím mít koulí červené barvy a kolik modré barvy, aby hra byla spravedlivá? Studenti tápali, ale přece jenom našli řešení, že koule modré barvy musí být jen jedna a koule červené barvy tři nebo obráceně.

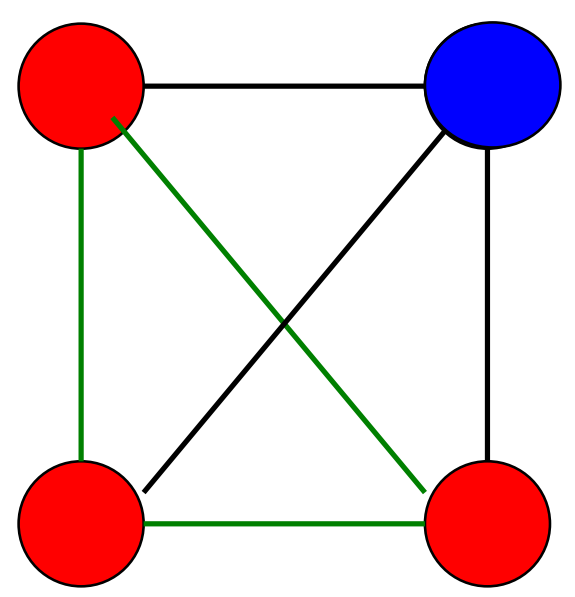

Obrázok 3 Grafický důkaz

Pravděpodobnost jevu $s$ koule stejné barvy jsou 3/6, což je $1 / 2$ a pravděpodobnost jevu $\boldsymbol{r}$ koule různé barvy $3 / 6$, což je také $1 / 2$. Hra je spravedlivá. 
Úloha 3: Matka má genotyp Aa. Stejný genotyp má i otec. Jaký genotyp může mít jejich potomek Dítě přebírá jedno písmeno z genotypu matky a jedno písmeno $\mathrm{z}$ genotypu otce. Pro každý z genotypů potomka najdi pravděpodobnost možnosti vzniku. Genotypy Aa a aA jsou totožné. (Poznámka: V genetice velké písmeno značí gen dominující a malé písmeno gen recesivní (ustupující)).

Opět si utvořme probabilistický model spojení dvou zárodečných buněk (heterezygot) (Obrázok 4):

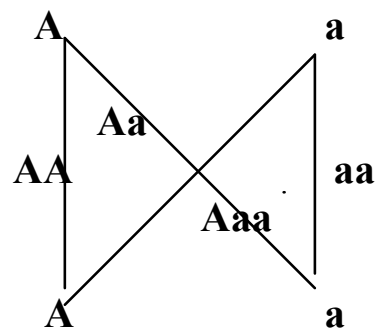

Obrázok 4

V analogii mezi obrázkem 1 a obrázkem 4 je vidět, že spojení dvou heterozygot je možné simulovat hodem dvou stejných mincí.

Odpověd' na naší úlohu je, že pravděpodobnost vzniku potomka s genotypem AA je $1 / 4, s$ genotypem aa též $1 / 4$ a s genotypem aa je $1 / 2$.

Podívejme se na výskyt genotypů $\mathrm{v}$ další generaci a spočítejme jejich pravděpodobnost:

\begin{tabular}{|c|c|c|c|}
\hline & $\begin{array}{c}\mathbf{A A} \\
0,25\end{array}$ & $\begin{array}{c}\mathbf{a a} \\
0,25\end{array}$ & $\begin{array}{l}\mathbf{A a} \\
0,5\end{array}$ \\
\hline $\begin{array}{l}\mathbf{A A} \\
0,25 \\
\end{array}$ & AA & Aa...........1 & $\begin{array}{l}\text { AA........0,5 } \\
\text { Aa.........0,5 }\end{array}$ \\
\hline $\begin{array}{c}\mathbf{a a} \\
0,25\end{array}$ & Aa.........1 & aa..........1 & $\begin{array}{r}\text { aa...........0,5 } \\
\text { Aa........ 0,5 } \\
\end{array}$ \\
\hline $\begin{array}{l}\mathbf{A a} \\
0,5\end{array}$ & $\begin{array}{l}\text { Aa......0,5 } \\
\text { AA.....0,5 }\end{array}$ & $\begin{array}{l}\text { aа........0,5 } \\
\text { Аa......0,5 }\end{array}$ & $\begin{array}{l}\text { aa..........0,25 } \\
\text { Aa.........0,50 } \\
\text { AA........0.25 }\end{array}$ \\
\hline
\end{tabular}

Spočítáme pravděpodobnost výskytu v nové generaci, kterou označíme $\mathrm{f}$ jako frekvence. Jde o nezávislé jevy.

f(AA):

$\mathrm{f}(\mathbf{A A}) \cdot \mathrm{f}(\mathbf{A A}) \cdot 1=0,25 \cdot 0,25 \cdot 1=0,0625$

$\mathrm{f}(\mathbf{A A}) \cdot \mathrm{f}(\mathbf{A a}) \cdot 0,5=0,25 \cdot 0,5 \cdot 0,5=0,0625$

$\mathrm{f}(\mathbf{A a}) \cdot \mathrm{f}(\mathbf{A A}) \cdot 0,5=0,5 \cdot 0,25 \cdot 0,5=0,0625$

$\mathrm{f}(\mathbf{A a}) \cdot \mathrm{f}(\mathbf{A a}) \cdot 0,25=0,5 \quad .0,5 \quad .0,25=0,0625$

$\mathrm{f}(\mathbf{A A})=0,625+0,625+0,625+0,625=\mathbf{0 , 2 5}$ 
f(aa):

$\mathrm{f}(\mathbf{a a}) \cdot \mathrm{f}(\mathbf{a a}) \cdot 1=0,25 \cdot 0,25 \cdot 1=0,625$

$\mathrm{f}(\mathbf{a a}) \cdot \mathrm{f}(\mathbf{A a}) \cdot 0,5=0,25 \cdot 0,5 \cdot 0,5=0,0625$

$\mathrm{f}(\mathbf{A a}) \cdot \mathrm{f}(\mathbf{a a}) \cdot 0,5=0,5 \cdot 0,25 \cdot 0,5=0,0625$

$\mathrm{f}(\mathbf{A a}) \cdot \mathrm{f}(\mathbf{A a}) \cdot 0,25=0,5.0,5.0,25=0,0625$

$f(\mathbf{A A})=0,0625+0,0625+0,0625+0,0625=\mathbf{0 , 2 5}$

$\mathrm{f}(\mathbf{A a})$ :

$\mathrm{f}(\mathbf{A A}) \cdot \mathrm{f}(\mathbf{a a}) \cdot 1=0,25 \cdot 0,25 \cdot 1=0,0625$

$\mathrm{f}(\mathbf{A A}) \cdot \mathrm{f}(\mathbf{A a}) \cdot 0,5=0,25 \cdot 0,5 \cdot 0,5=0,0625$

$\mathrm{f}(\mathbf{a a}) \cdot \mathrm{f}(\mathbf{A A}) \cdot 1=0,25 \cdot 0,25 \cdot 1=0,0625$

$\mathrm{f}(\mathbf{a a}) \cdot \mathrm{f}(\mathbf{A a}) \cdot 0,5=0,25 \cdot 0,5 \cdot 0,5=0,0625$

$\mathrm{f}(\mathbf{A a}) \cdot \mathrm{f}(\mathbf{A A}) \cdot 0,5=0,5 \cdot 0,25 \cdot 0,5=0,0625$

$\mathrm{f}(\mathbf{A a}) \cdot \mathrm{f}(\mathbf{a a}) \cdot 0,5=0,5 \cdot 0,25 \cdot 0,5=0,0625$

$\mathrm{f}(\mathbf{A a}) \cdot \mathrm{f}(\mathbf{A a}) \cdot 0,5=0,5 \cdot 0,5.0,5=0,1250$

$\mathrm{f}(\mathbf{A a})=0,0625+0,0625+0,0625+0,0625+0,0625+0,0625+0,125$

$=\mathbf{0 , 5}$

Přesvědčili jsme se, že pravděpodobnost výskytu v nové generaci je shodná $\mathrm{s}$ výskytem $\mathrm{v}$ generaci původní.

Výsledek studenti ověřovali experimentálně. V jednom neprůhledném sáčku byl kruh z umělé hmoty na obou stranách černý - genotyp AA, identický kruh na obou stranách bílý- genotyp aa a dva identické kruhy z jedné strany bílé a z druhé strany černé - genotyp Aa (populace matek) a v druhém sáčku stejné kruhy (populace otců). Studenti vytáhli jeden kruh z jednoho sáčku aa druhý kruh z druhého sáčku a nehledíc na ně, rychle je položili na stůl. Viditelné barvy kruhu charakterizují gen potomka. Výsledky pokusů zapisovali.

Studentům jsem se zmínil i o známém pokusu kř́žení hrachu moravským botanikem J.G. Mendelem (1822-1884), kdy gen A je nositelem červené barvy květu a gen a bílé barvy květu.

Rostliny o genotypu Aa mají květy růžové. V určitém roce měl na pokusném pozemku všechny květy růžové (viz úloha 3 - genotyp matky Aa, genotyp otce Aa). V následujícím roce byly na pokusném pozemku květy růžové, červené a bílé. Květů červených bylo právě tolik jako bílých a květů růžových bylo dvakrát více než červených (bílých).

Dále pokračovala výuka určováním frekvence genotypů a fenotypů krevních skupin v populaci a i ukázka jedné z metod při vylučování otcovství v soudních sporech.

Tabulka 1 Genotypy a fenotypy $v$ populaci

\begin{tabular}{|c|c|c|c|}
\hline Genotyp & Fenotyp & Frekvence genotypu & $\begin{array}{c}\text { Frekvence } \\
\text { fenotypu }\end{array}$ \\
\hline AA & A & 0,08 & 0,41 \\
A0 & & 0,33 & 0,18 \\
\hline BB & B & 0,02 & \\
B0 & & 0,16 & 0,08 \\
\hline AB & AB & 0,08 & 0,33 \\
\hline $\mathbf{0 0}$ & $\mathbf{0}$ & 0,33 & \\
\hline
\end{tabular}


Před narozením dítěte lze s určitou pravděpodobností určit jakou bude mít dítě krevní skupinu na základě krevní skupiny otce a matky.

Lidově řečeno: „Dítě přebírá jedno písmeno z genotypu matky a jedno písmeno z genotypu otce“. Matematicky řečeno: Má-li matka krevní genotypovou skupinu $x x$ a otec krevní genotypovou skupinu $\boldsymbol{x y}$, pak dítě může mít genotypovou krevní skupinu $\boldsymbol{x} \boldsymbol{x}$ s pravděpodobností 0,5 . Pro frekvenci genotypů platí, že $\mathrm{f}_{x x}+\mathrm{f}_{x y}=1$.

Sestavíme tabulku genotypů a fenotypů otce, matky a dítěte.

Tabulka 2 Tabulka genotypů a fenotypů otce, matky a dítěte

\begin{tabular}{|c|c|c|c|c|c|c|c|}
\hline \multirow{2}{*}{\multicolumn{2}{|c|}{ matka }} & \multicolumn{2}{|c|}{$\mathbf{A}$} & \multicolumn{2}{|c|}{ B } & \multirow{3}{*}{$\begin{array}{c}\mathbf{A B} \\
0,08\end{array}$} & \multirow{3}{*}{$\begin{array}{c}\mathbf{0 0} \\
0,33\end{array}$} \\
\hline & & \multirow{2}{*}{$\begin{array}{c}\mathbf{A A} \\
0,08\end{array}$} & \multirow{2}{*}{$\begin{array}{l}\mathbf{A 0} \\
0,33\end{array}$} & \multirow{2}{*}{$\begin{array}{l}\text { BB } \\
0,02\end{array}$} & \multirow{2}{*}{$\begin{array}{l}\text { B0 } \\
0,16\end{array}$} & & \\
\hline ote & & & & & & & \\
\hline \multirow[t]{2}{*}{$\mathbf{A}$} & $\begin{array}{l}\mathbf{A A} \\
0,08\end{array}$ & AA $\ldots \ldots . .1$ & $\begin{array}{l}\text { АA......0,5 } \\
\text { A0......0,5 }\end{array}$ & $\mathbf{A B} \ldots \ldots 1$ & $\begin{array}{l}\text { AB.....0,5 } \\
\text { A0.....0,5 }\end{array}$ & $\begin{array}{l}\mathbf{A A} \ldots . .0,5 \\
\mathbf{A B} \ldots . .0,5\end{array}$ & A0.....1 \\
\hline & $\begin{array}{l}\mathbf{A 0} \\
0,33\end{array}$ & $\begin{array}{l}\mathbf{A A} \ldots . . .0,5 \\
\text { A0---- } 0,5\end{array}$ & $\begin{array}{l}\text { АA.....0,25 } \\
\text { А0......0,5 } \\
\mathbf{0 0} \ldots \ldots . .0,25\end{array}$ & $\begin{array}{l}\text { AB.....0,5 } \\
\text { B0......0,5 }\end{array}$ & $\begin{array}{l}\mathbf{A B} \ldots \ldots . . .0,25 \\
\text { A0......0,25 } \\
\text { B0......0,25 } \\
\text { 00.......0,25 }\end{array}$ & $\begin{array}{l}\mathbf{A A} \ldots . .0,25 \\
\text { AB } \ldots . .0,25 \\
\text { A0....0,25 } \\
\text { B0....0,25 }\end{array}$ & $\begin{array}{l}\text { A0...0,5 } \\
00 \ldots . . .0,5\end{array}$ \\
\hline \multirow[t]{2}{*}{ B } & $\begin{array}{l}\text { BB } \\
0,02\end{array}$ & $\overline{A B} \ldots . .1$ & $\begin{array}{l}\text { AB } \ldots \ldots . .0,5 \\
\text { B0.......0,5 }\end{array}$ & BB.......1 & $\begin{array}{l}\text { BB.......0,5 } \\
\text { B0.......0,5 }\end{array}$ & $\begin{array}{l}\text { AB....0,5 } \\
\text { BB.....0,5 }\end{array}$ & B0.......1 \\
\hline & $\begin{array}{l}\text { B0 } \\
0,16\end{array}$ & $\begin{array}{l}\mathbf{A B} \ldots \ldots 0,5 \\
\mathbf{A 0} \ldots \ldots 0,5\end{array}$ & $\begin{array}{l}\text { AB..... } 0,25 \\
\text { A0......0, } 25 \\
\text { B0.......0, } 25 \\
\mathbf{0 0 . . . . . . . 0 0 , 2 5 ~}\end{array}$ & $\begin{array}{l}\text { BB.....0,5 } \\
\text { B0......0,5 }\end{array}$ & $\begin{array}{l}\text { ВВ.......0,25 } \\
\text { В0........0,5 } \\
\text { 00..........0,25 }\end{array}$ & $\begin{array}{l}\text { AB.....0,25 } \\
\text { A0.....0,25 } \\
\text { BB.....0,25 } \\
\text { B0.....0,25 }\end{array}$ & $\begin{array}{l}\text { B0....0,5 } \\
\text { 00.....0,5 }\end{array}$ \\
\hline \multicolumn{2}{|c|}{$\begin{array}{l}\mathbf{A B} \\
0,08\end{array}$} & $\begin{array}{l}\mathbf{A A} \ldots . .0,5 \\
\mathbf{A B} \ldots . .0,5\end{array}$ & 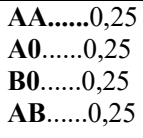 & $\begin{array}{l}\text { AB.....0,5 } \\
\text { BB.....0,5 }\end{array}$ & $\begin{array}{l}\text { AB.......0,25 } \\
\text { A0.......0,25 } \\
\text { BВ.......0,25 } \\
\text { В0.......0,25 }\end{array}$ & $\begin{array}{l}\text { AA....0,25 } \\
\text { AB.....0,5 } \\
\text { BB......0,25 }\end{array}$ & $\begin{array}{l}\text { A0....0,5 } \\
\text { B0....0,5 }\end{array}$ \\
\hline \multicolumn{2}{|c|}{$\begin{array}{c}\mathbf{0 0} \\
0,33\end{array}$} & A0......1 & $\begin{array}{l}\text { A0 .....0,5 } \\
\text { 00..... } 0,5\end{array}$ & B0.......1 & $\begin{array}{l}\text { B0.........0,5 } \\
\text { 00........0,5 }\end{array}$ & $\begin{array}{l}\text { A0.....0,5 } \\
\text { В0......0,5 }\end{array}$ & $00 \ldots 1$ \\
\hline
\end{tabular}

Z tabulky vidíme například: Má-li otec genotypovou krevní skupinu AA a matka genotypovou krevní skupinu A0 nemůže mít dítě krevní genotypovou skupinu BB, B0, AB a 00. Pravděpodobnost výskytu těchto skupin je nulová. Má-li otec fenotypovou krevní skupinu A a matka také A, nemůže mít dítě fenotypovou krevní skupinu $\mathbf{B}$ nebo $\mathbf{A B}$.

Spočítáme-li pravděpodobnost frekvence genotypů v nové generaci dojdeme ke stejné frekvenci jako měla původní populace.

Napríklad: Frekvence genotypu AA v populaci je 0,08. Tedy $\mathrm{F}(\mathbf{A A})=0,08$. Spočítáme frekvenci genotypu AA v nové generaci. Jde o nezávislé jevy.

Výpočet:

$$
\mathrm{f}(\mathbf{A A}) \cdot \mathrm{f}(\mathbf{A A}) \cdot 1=0,08 \quad \cdot 0,08 \cdot 1=0,0064
$$

Slavonic Pedagogical Studies Journal, ISSN 1339-866o, Volume 5 Issue 1, February 2016 


$$
\begin{aligned}
& \mathrm{f}(\mathbf{A A}) \cdot \mathrm{f}(\mathbf{A 0}) \cdot 0,5=0,08 \quad \cdot 0,08 \cdot 0,5=0,0132 \\
& \mathrm{f}(\mathbf{A A}) \cdot \mathrm{f}(\mathbf{A B}) \cdot 0,5=0,08 \cdot 0,08 \cdot 0,5=0,0032 \\
& \mathrm{f}(\mathbf{A 0}) \cdot f(\mathbf{A A}) \cdot 0,5=0,33 \quad \cdot 0,08 \cdot 0,5=0,0132 \\
& \mathrm{f}(\mathbf{A 0}) \cdot f(\mathbf{A 0}) \cdot 0,25=0,33 \quad .0,33.0,25=0,027225 \\
& \mathrm{f}(\mathbf{A 0}) \cdot f(\mathbf{A B}) \cdot 0,25=0,33 \quad \cdot 0,08 \quad .0,25=0,0066 \\
& \mathrm{f}(\mathbf{A B}) \cdot \mathrm{f}(\mathbf{A A}) \cdot 0,5=0,08 \cdot 0,08 \cdot 0,5=0,0032 \\
& \mathrm{f}(\mathbf{A B}) \cdot \mathrm{f}(\mathbf{A 0}) \cdot 0,25=0,08 \quad .0,33 \cdot 0,25=0,0066 \\
& \mathrm{f}(\mathbf{A B}) \cdot \mathrm{f}(\mathbf{A B}) \cdot 0,25=0,08 \cdot 0,08 \cdot 0,25=0,0016
\end{aligned}
$$

Sečteme frekvence genotypů $\mathrm{v}$ nové generaci:

$0,0064+0.0132+0,0032+0,0132+0,027224+0,0066+0,0032+0,066$

$+0,0016=$

$=0,081225=\mathbf{0 , 0 8}$ (zaokrouhleno)

V nové generaci je frekvence genotypu AA rovna 0,08, je stejná jako frekvence genotypu AA v původní populaci.

Výuka probíhala $v$ rámci řešení projektu CZ.1.07/2.3.00/45.0034 „Partnerstvím ke zkvalitnění přípravy lidských zdrojů pro přírodovědné a technické vzdělávání" spolufinancovaného Evropským sociálním fondem a státním rozpočtem České republiky v souladu s publikací Metodika badatelsky orientované výuky, která byla jedním z výstupu projektu. Mají-li učitele 1 . stupně základní školy $\mathrm{k}$ badatelské výuce, musí se $\mathrm{v}$ prvé řadě seznámit s badatelskou výukou sami.

\section{Bibliographic references:}

PŁOCKI, A. 2001. Pravdepodobnost kolem nas, Usti nad Labem: UJEP. ISBN 80-704-55-3.

SKODA, J. - DOULIK, P. 2015. 1. Vyuziti nekterych psychodidaktickych poznatku pri uceni a vyucovani. In Metodika badatelsky orientovane vyuky. Usti nad Labem, UJEP.

MELICHAR, J. 2015. 6. Badatelsky orientovana vyuka v matematice. In Metodika badatelsky orientovane vyuky, Usti nad Labem, UJEP.

prof. RNDr. Jan Melichar, CSc.,

Faculty of Education

University of J. E. Purkyně in Ústí nad Labem

Hoření 13, 40096 Ústí nad Labem

Czech Republic

jan.melichar@ujep.cz 